\title{
Елена БОЛДЫРЕВА
}

\section{СТРАТЕГИЯ ФИНЛЯНДИИ В АФРИКЕ}

\begin{abstract}
Аннотация. В статье анализируется стратегия Финляндии в отношении Африки. Актуальность данной темы объясняется ростом интереса не только Финляндии, но и Европейского союза к Африке, особенно к странам Сахеля. Стратегия Финляндии принималась практически одновре́менно с аналогичным документом ЕС и может рассматриваться как его составная часть. В статье проанализированы находящиеся в открытом доступе документь МИД Финляндии касательно политики этой северной страны в отночении как континента в иелом, так и отдельных стран Африки. Предназначение Стратегии в том, чтобы ставить реалистичные, но амбициозные цели для африканской политики Финляндии, исходя из общих интересов обеих сторон, определить конкретные действия по их достижению. Подчёркнута необходимость уделять особое внимание укреплению политических и экономических отношений, расширять сотрудничество в различных формах. Таким образом, проведённый анализ может быть полезным для лучшего понимания данного направления внешней политики Финляндии.
\end{abstract}

Ключевые слова: Финляндия, Африка, Сахель, Стратегия, Европейский Союз, МИД.

\section{Рост в Европе интереса к Африке}

За последние 10-15 лет стратегическое, торговое и экономическое значение африканского континента и его государств возросло. Африканский союз укрепил свои позиции в качестве международного игрока и партнёра. Там сталкиваются интересы великих держав, усиливается конкуренция за рынки и ресурсы многих африканских стран. Во всём мире очевидно усиление внимания к Африке, чему свидетельством стало появление в последнее время большого количества публикаций, особенно посвящённых региону Сахель ${ }^{1}$.

На протяжении последних лет многие страны континента демонстрировали устойчивый экономический рост, расширяли взаимодействие на основе Соглашения о континентальной свободной торговле. Однако пандемия Covid-19 замедлила экономическое развитие в Африке, результаты которого не будут соответствовать потребностям, связанным с ростом населения. Пандемия также может помешать осуществлению Повестки дня на период до 2030 г., вызвать нестабильность, ослабить процессы демократизации и резко увеличить необходимость внешней гуманитарной помощи.

Африканский континент всё более становится объектом политики ЕС, но не очевидно, что он сохранит статус крупнейшего партнёра Африки в сферах торговли, инвестиций и развития. ЕС продолжает диверсифицировать свои отношения с «чёрным континентом» - не-

\footnotetext{
(C) Болдырева Елена Леонардовна - кандидат политических наук, доцент, Высшая школа международных отношений, Санкт-Петербургский политехнический университет Петра Великого. Aдрес: 195251, Россия, Санкт-Петербург, ул. Политехническая, д. 29.E-mail: boldyreva_el@ spbstu.ru.

Статья поступила в редакцию: 21.01.2021.

${ }^{1}$ What to Watch in Sub-Saharan Africa in 2021. CSIS. URL: https://www.csis.org/analysis/what-watch-sub-saharanafrica-2021 (дата обращения 15.01.2021).
} 
сколько европейских стран расширили своё присутствие там. Брюссель прилагает систематические и долгосрочные усилия по содействию стабильности и развитию в Африке посредством таких действий, как операции по урегулированию кризисов и сотрудничество в целях развития, а также путём поддержки создания африканского потенциала управления кризисами и предотвращения конфликтов ${ }^{1}$.

Хотя подход ЕС и предусматривает эффективное использование всех инструментов своей внешней политики, но на практике ещё многое предстоит улучшить. Одним из вариантов для Евросоюза может быть централизация его деятельности по анализу, отчетности и координации в какой-то одной точке на континенте. Также ЕС должен уделять больше внимания местной динамике, что поможет ему более чётко сконцентрировать своё внимание на потребностях граждан и общества в регионе. Наконец, Брюссель должен внимательно изучить баланс между своими краткосрочными и долгосрочными целями.

Вопросы совершенствования его деятельности на континенте освещены в Стратегии Европейского союза в отношении Африки ${ }^{2}$, принятой 9 марта $2020 \Gamma^{3}$. В том же году Министерство иностранных дел Финляндии разработало собственную Стратегию развития связей со странами этого континента ${ }^{4}$. Подготовка в 2020 г. этого документа в Хельсинки проходила параллельно с принятием вышеупомянутой Стратегии ЕС, и в ней, в основном, содержатся аналогичные цели и задачи.

\section{Содержание и цели африканской Стратегии Финляндии}

Правительство Финляндии обратилось к теме сотрудничества с Африкой, судя по всему, ещё в 2018 г., когда тогдашний министр иностранных дел Т. Сойни подчеркнул, что «главный вызов во внешней политике Финляндии и ЕС на данный момент связан с Африкой» 5 . По его словам, «среди наиболее быстро растущих экономик мира половина приходится на африканские страны. Развитию их экономики способствует также решение Африканского союза о создании собственной зоны свободной торговли, в состав которой вошли уже 49 государств» 6 .

Процесс же непосредственной разработки финской стратегии был начат весной и летом 2020 г., когда данный документ был подготовлен тематическими рабочими группами центрального правительства. Основная работа была проделана Департаментом Африки и Ближнего Востока, который как раз и занимается вопросами политическими, торгово-экономическими и сотрудничества в области развития в контексте двусторонних отношений Финляндии и внешних связей ЕС со странами данного континента.

В том же 2020 г. был опубликован правительственный доклад о внешней политике и политике безопасности страны ${ }^{7}$, где отношениям со странами Африки посвящено несколько страниц. В докладе отмечено, что Финляндия уже имеет прочные дипломатические и торговые отношения со странами Африки, но есть и потенциал для углубления взаимодействия.

\footnotetext{
${ }^{1}$ Iso-Markku T., Tammiko T. The EU`s role and policies in the Sahel. FIIA briefing paper. September 2020 (290). URL: https://www.fiia.fi/wp-content/uploads/2020/09/bp290_the-eus-role-and-policies-in-the-sahel.pdf (дата обращения 15.01.2021).

${ }^{2}$ Биссон Л.С. Новая стратегия ЕС для Африки: в поисках подлинного партнерства // Современная Европа. 2020. №3. C. 39-50.

${ }^{3}$ Там же.

${ }_{5}^{4}$ Finland's Africa Strategy. URL: https://um.fi/finland-s-africa-strategy (дата обращения 15.01.2021).

5 Министр иностранных дел Тимо Сойни назвал Африку одним из приоритетных проектов финской внешней политики. YLE. URL: https://yle.fi/uutiset/osasto/novosti/ministr_inostrannykh_del_timo_soini_nazval_afriku_odnim_iz prioritetnykh_proektov_finskoi_vneshnyei_politiki/10372409 (дата обращения 15.01.2021). ${ }^{6}$ Ibid.

${ }^{7}$ Government Report on Finnish Foreign and Security Policy. Publications of the Finnish government 2020. URL: https://julkaisut.valtioneuvosto.fi/bitstream/handle/10024/162515/VN_2020_32.pdf?sequence=1\&isAllowed=y (дата обращения 15.01.2021).
}

Научно-аналитический вестник ИЕ РАН, 2021, №1 
Как написано в Стратегии, особое внимание будет уделяться расширению и углублению связей Финляндии с африканскими странами, Африканским союзом и другими региональными организациями этого континента. Стратегия также направлена на выявление общих интересов и укрепление связей в различных секторах между Финляндией и Африкой.

Нынешний министр иностранных дел Финляндии Пекка Хаависто в своей статье от 22 декабря 2020 г., подводя промежуточный итог внешней политики Финляндии, уделил достаточно внимания и отношениям с Африкой ${ }^{1}$. В статье говорится, что для такой небольшой страны, как Финляндия, внешняя политика, основанная на ценностях, является практическим выбором, который помогает защищать и собственные интересы. Многие учёные, политики и общественные деятели из разных областей и секторов экономики и культуры участвовали в консультациях по Африканской стратегии и Отчёту о правах человека. Эти обсуждения показали, что чем амбициознее Финляндия планирует продвигать свои интересы, тем требуется больше усилий и ещё большего объёма сотрудничества.

Основными темами такого сотрудничества объявлены следующие: мир и безопасность, торговля и экономика, климат, окружающая среда и природные ресурсы, образование, молодёжь, положение женщин, вопросы, связанные с миграцией, а также система ценностей (права человека, демократия, правовое государство и равенство) ${ }^{2}$.

\section{Гуманитарные и экономические аспекты отношений Финляндии и африканских стран}

Полезно напомнить, что уже длительное время Финляндия оказывала и оказывает сегодня финансовую помощь различным африканским странам, таким как Сомали, Эфиопия, Кения, Мозамбик, Танзания, Эритрея и некоторым государствам Магриба. В 2007 г. завершено оказание помощи со стороны Хельсинки Египту и Намибии в связи с ростом экономического благополучия в этих странах. Весной 2017 г. Финский Красный Крест и Организация помощи зарубежным странам Евангелическо-лютеранской церкви Kirkon Ulkomaanapu занимались сбором средств в пользу голодающих в Йемене, Нигерии, Сомали и Южном Судане.

В течение 45 лет Финляндия оказывала помощь и Замбии, но в 2019 г. было принято решение её прекратить из-за допущенных замбийской стороной финансовых нарушений. Последний транш этой стране будет предоставлен в 2023 г. Согласно полученным от МИД данным, с 2015 по 2018 гг. это ведомство «рассмотрело 20 дел о нарушениях, связанных с помощью развивающимся странам. Из них 11 касались именно Замбии. В семи замбийских случаях было принято решение об истребовании уже выделенных сумм, которые варьировались от 2 до 70 тыс. евро»${ }^{3}$.

В данной связи интерес представляет документ под названием «Оценка программ сельского хозяйства, развития сельских районов и лесного сектора в Африке», разработанный Министерством иностранных дел Финляндии для выявления актуальных и эффективных подходов и инструментов для поддержки реализации текущих программ и планирования будущего сотрудничества в этих секторах ${ }^{4}$. Можно с уверенностью предположить, что наиболее тес-

\footnotetext{
${ }^{1}$ Minister for Foreign Affairs Pekka Haavisto: Foreign Policy Year 2020. URL: https://um.fi/current-affairs/article//asset_publisher/iYk2EknIlmNL/content/ulkoministeri-pekka-haavisto-ulkopolitiikan-vuosi-2020 (дата обращения 15.01.2021).

${ }_{3}^{2}$ Finland's Africa Strategy. URL: https://um.fi/finland-s-africa-strategy (дата обращения: 15.01.2021).

3 Финляндия прекращает помощь Замбии из-за финансовых нарушений. YLE. URL: https://yle.fi/uutiset/osasto/ novosti/finlyandiya_prekrashchaet_pomoshch_zambii_iz-za_finansovykh_narushenii/10651213 (дата обращения 15.01.2021).

${ }^{4}$ Evaluation of the agriculture, rural development and forest sector programmes in Africa. Evaluation on Finland's Development Policy and Cooperation, August 2019. URL: https://um.fi/documents/384998/0/ARDF+Evaluation_Final+ Report.pdf/043c849a-ac67-903d-30ad-5a0299b34247?t=1569774427362 (дата обращения 15.01.2021).
} 
ные в этом секторе отношения у Финляндии развиваются с Эфиопией, Кенией, Мозамбиком, Танзанией и Замбией, поскольку именно им посвящены на сайте МИД многостраничные доклады ${ }^{1}$. В отдельном докладе дана среднесрочная оценка ситуации в сфере здравоохранения и биозащищённости в Танзании ${ }^{2}$, где проанализированы возможности этого сектора в борьбе с биологическими угрозами и снижению вероятности вспышек инфекционных заболеваний.

Что касается миграции из Африки, то, по данным Статистического управления Финляндии на конец 2019 г., в Суоми проживает 54450 выходцев из различных африканских стран, что составляет порядка $1 \%$ всего населения. Из них почти $82 \%$ прибыли в Финляндию из стран южнее Сахары, больше всего из Сомали (почти 22 тыс. человек) и от 3 до 4 тыс. человек из Нигерии ${ }^{3}$, Марокко, Демократической Республики Конго и Эфиопии ${ }^{4}$.

По данным же таможенной статистики Финляндии за 2019 г., ни одна африканская страна не входит в число 15 крупнейших торговых партнёров Финляндии, и вообще вся Африка проходит по категории «другие страны», не относящиеся к Европе, Азии и Северной Америке, и составляет 5,9\% во внешнеторговом обороте Суоми ${ }^{5}$. В суммарном выражении за период с января по ноябрь 2020 г., крупнейшими торговыми партнёрами Финляндии в Африке были Марокко, Египет и ЮАР, с оборотами соответственно в 286, 187 и 81 млн евро 6 . Очевидно, что Финляндии хотелось бы изменить эти цифры в сторону увеличения.

Благодаря своим растущим рынкам многие африканские страны являются потенциальными торговыми партнёрами Финляндии. Отношения Суоми со странами к югу от Сахары основаны на опыте успешного сотрудничества в области развития, на котором можно строить планы более всестороннего взаимодействия.

Уже достаточно развиты политические и торговые отношения Финляндии со странами Северной Африки, но существует потенциал и для их расширения. Исследуемая стратегия направлена на выявление приоритетных областей сотрудничества в целях развития.

Таким образом, можно говорить о достаточно серьёных интересах Финляндии на африканском континенте и о её стремлении развивать экономические и другие отношения с партнёрами там.

Ситуация с безопасностью в странах Африки отражается и на положении дел в этой сфере в Финляндии. Последствия, например, политической нестабильности и конфликтов ещё больше усугубляются различными внешними акторами, причастными к гражданской войне в Ливии. Да и происходящее в регионах Сахель и Африканского рога отражается на ситуации с безопасностью в Европе.

Если вернуться к Стратегии, то отправной точкой, согласно этому документу, являются

\footnotetext{
${ }^{1}$ Evaluation of Agriculture, Rural Development and Forest Sector Programmes in Africa. URL: https://um.fi/developm ent-cooperation-evaluation-reports-project-and-programme-evaluations/-/asset_publisher/nBPgGHSLrA13/content/eval uointi-maatalous-maaseutukehitys-ja-metsasektorin-kehityshankkeista-afrikassa/384998 (дата обращения 15.01.2021). ${ }^{2}$ Carlin E.P. Collogly C. Mid-Term Evaluation Strengthening Health Security and Biosecurity in Tanzania by Biodetection Capacity Building. Apartnership project of the Tanzanian Veterinary Laboratory Agency and the Centre for Military Medicine, Finnish Defence Forces. MTE Tanzania, United Republic of Tanzania, April 2-8, 2017.

${ }_{3}^{3}$ Болдырева Е.Л. Миграционные траектории и последствия миграции (на примере Нигерии) // Диалог культур в глобализирующемся мире. Диалог культур и культура диалога. Материалы Всероссийской научно-практической конференции / под ред. В.Э. Манаповой, О.С. Мутиевой. Махачкала, 2019. С. 102-104.

${ }_{4}^{4}$ Immigration and emigration by nationality, origin and language, 1990-2019. Tilastokeskus. URL: http://pxnet2. stat.fi/PXWeb/pxweb/en/StatFin/StatFin_vrm_muutl/statfin_muutl_pxt_11a8.px (дата обращения 15.01.2021).

${ }_{5}^{5}$ Finnish international trade 2019. Figures and diagrams. Finnish Customs Statistics. P. 31. URL: https://tulli.fi/docume nts/2912305/3439475/Finnish+international+trade+2019+-+Figures+and+diagrams/4ebae1ed-15b1-9269-4c69-ffbccee b6ee4/Finnish+international+trade+2019+-+Figures+and+diagrams.pdf (дата обращения 15.01.2021).

${ }^{6}$ Monthly statistics on the international trade in goods. November 2020. Official statistics of Finland. Helsinki 2021. P. 12. URL: https://tulli.fi/documents/2912305/3329364/Monthly+statistics\%2C+November+2020.pdf/8e53f526-581d-0e cc-1a35-f0ff31471582/Monthly+statistics\%2C+November+2020.pdf?t=1611839864856 (дата обращения 05.02.2021).
} 
собственные интересы и компетенция Финляндии, а также такие базовые документы, как По вестка дня на период до 2030 г., Повестка дня Африканского союза «Африка, которую мы хотим» ${ }^{1}$ В стратегии Финляндии также учитываются направления политики Европейского союза в отношении Африки ${ }^{2}$. Во всех упомянутых документах говорится о том, что по мере развития экономики стран Африки и роста их населения, роль африканских стран в мировой политике и экономике становится всё более заметной.

* $\quad * \quad *$

Стратегия Финляндии в отношении Африки принята недавно, меньше года назад, поэтому говорить о каких-то успехах рано. Но не вызывает сомнения тот факт, что стратегическое, торговое и экономическое значение африканского континента и его государств возросло. Африканский союз укрепил свои позиции в качестве международного игрока и партнёра.

Предназначение Стратегии в том, чтобы ставить реалистичные и одновре́менно амбициозные цели для политики Финляндии в отношении Африки, исходя из общих интересов Суоми и африканских стран, определить конкретные действия по их достижению.

На протяжении последних лет многие страны континента демонстрировали устойчивый экономический рост, расширили взаимодействие на основе Соглашения о континентальной свободной торговле. Однако пандемия Covid-19 замедлила экономическое развитие в Африке, которое не будет в состоянии соответствовать потребностям, связанным с ростом населения. Пандемия также может помешать осуществлению Повестки дня на период до 2030 г., вызвать нестабильность, ослабить процессы демократизации и резко увеличить необходимость внешней гуманитарной помощи. Проблемы с доступом к образованию, здравоохранению, проблемы с трудоустройством молодёжи могут обострить восприятие неравенства, создать питательную среду для экстремизма и терроризма, привести к внутренней дестабилизации.

\section{Список литературы}

Биссон Л.С. Новая стратегия ЕС для Африки: в поисках подлинного партнёрства // Современная Европа. 2020. №3. С. 39-50. DOI: 10.15211/soveurope320203950

Болдырева Е.Л. Миграционные траектории и последствия миграции (на примере Нигерии) // Диалог культур в глобализирующемся мире. Диалог культур и культура диалога. Материалы Всероссийской научно-практической конференции / под ред. В.Э. Манаповой, О.С. Мутиевой. Махачкала, 2019. С. 102-104.

Гришина Н.Ю., Болдырева Е.Л., Дуйсембина Е.Ю. Влияние интернет-технологий на процесс принятия решения как новый политический тренд (на примере компании «Кембридж Аналитика») // Научно-технические ведомости СПбГПУ. Гуманитарные и общественные науки. 2019. Т. 10. №1. С. 69-80. DOI: 10.18721/JHSS.10107

Худолей К.К., Ланко Д.А. Финская дилемма безопасности, НАТО и фактор Восточной Европы // Мировая экономика и международные отношения. 2019. №3. С. 13-20. DOI: 10.20542/0131-2227-2019-63-3-13-20

\section{References}

Bisson, L.S. (2020). Novaja strategija ES dlja Afriki: v poiskah podlinnogo partnerstva [The

\footnotetext{
1 Agenda 2063: The Africa We Want - EU. URL: https:/au.int/en/agenda2063/overview (дата обращения 15.01.2021).

${ }^{2}$ Биссон Л.С. Указ. соч. С. 39-50.
}

Научно-аналитический вестник ИЕ РАН, 2021, №1 
EU's New Strategy for Africa: in Search of a Genuine Partnership]. Sovremennaja Evropa [Contemporary Europe]. 3. P. 39-50. (In Russian). DOI: 10.15211/soveurope320203950

Boldyreva, E.L. (2019). Migracionnye traektorii i posledstvija migracii (na primere Nigerii) [Migration trajectories and consequences of migration (on the example of Nigeria)]. In: Manapova V.Je., Mutieva O.S. (eds.) (2019). Dialog kul'tur v globalizirujushhemsja mire. Dialog kul'tur i kul'tura dialoga. Materialy Vserossijskoj nauchno-prakticheskoj konferencii [Dialogue of cultures in a globalizing world. Dialogue of cultures and culture of dialogue]. P. 102-104. (In Russian).

Iso-Markku, T., Tammiko, T. (2020). The EU's role and policies in the Sahel. FIIA briefing paper. Available at: https://www.fiia.fi/wp-content/uploads/2020/09/bp290_the-eus-role-and-policiesin-the-sahel.pdf (accessed 15.01.2021).

Matveevskaya, A.S. Pogodin, S.N. (2017). The essence of cross-cultural conflict (Presentation of a problem). Vestnik Sankt-Peterburgskogo Universiteta, Filosofiia i Konfliktologiia [Bulletin of St. Petersburg University. Philosophy and Conflictology]. 33(1). P. 115-118. DOI: 10.21638/11701/spbu17.2017.112

Matveevskaya, A.S. Pogodin, S.N. (2018). Integration of migrants as a way to diminish proneness to conflict in multinational communities. Vestnik Sankt-Peterburgskogo Universiteta, Filosofiia i Konfliktologiia [Bulletin of St. Petersburg University. Philosophy and Conflictology]. 34(1). DOI: 17-23 2018 10.21638/11701/spbu17.2018.110

Carlin, E.P. Collogly, C. (2017). Mid-Term Evaluation Strengthening Health Security and Biosecurity in Tanzania by Biodetection Capacity Building. A partnership project of the Tanzanian Veterinary Laboratory Agency and the Centre for Military Medicine, Finnish Defence Forces. MTE Tanzania, United Republic of Tanzania.

\section{Finland's Africa Strategy}

Author. Elena Boldyreva, Candidate of Political Sciences, associate professor, Department of International Relations, Peter the Great St. Petersburg Polytechnic University. Address: 29, Polytechnicheskaya str., Saint-Petersburg, Russia, 195251. E-mail: boldyreva_el@ spbstu.ru.

Abstract. The article analyzes Finland's strategy towards Africa. The relevance of this topic does not raise doubts in the light of the growing interest not only of Finland, but also of the European Union as a whole in Africa, especially the countries of the Sahel. Finland's strategy was adopted almost simultaneously with the EU's strategy and can be considered as an integral part of it. The article analyzes the publicly available documents of the Ministry of Foreign Affairs of Finland, which are relevant both to the policy of this northern country in relation to the continent as a whole and to individual African countries. The aim of the strategy is to set realistic but ambitious goals for Finland's policy towards Africa, based on the common interests of Finland and African countries, to define the main directions of Finland's policy towards Africa and to define concrete actions to achieve them. In addition, it is necessary to pay special attention to strengthening political and economic relations and expand cooperation in various forms. Thus, the research carried out can be useful for a better understanding of one of the most important directions of Finnish foreign policy today.

Key words: Finland, Africa, Sahel, Strategy, European Union, Ministry of Foreign Affairs.

DOI: http://dx.doi.org/10.15211/vestnikieran120213237 